\title{
CARACTERIZAÇÃO SOROLÓGICA DOS ANTÍGENOS DE SUPERFÍCIE EM CEPAS DE ESCHERICHIA COLIISOLADAS DE SUÍNOS COM DIARRÉIA NO ESTADO DO PARANÁ
}

\author{
(Serological characterization of surface antigens in Escherichia coli strains \\ isolated from swine with diarrhea in Parana State)
}

\author{
SOUZA, C. ; WARTH, J.F.G. ${ }^{2}$; HAMANN, W. ${ }^{2}$; BIESDORF, S.M. ${ }^{3}$ \\ ${ }^{1}$ Docente da UFPR - Campus Palotina, PR \\ ${ }^{2}$ Departamento de Medicina Veterinária, UFPR, Curitiba, PR \\ ${ }^{3}$ Centro de Diagnóstico Marcos Enrietti, SEAB, Curitiba, PR
}

\begin{abstract}
RESUMO - O presente trabalho teve como objetivo a caracterização sorológica de 42 cepas de Escherichia coli isoladas no Centro de Diagnóstico Marcos Enrietti em Curitiba, PR de surtos de diarréia suína no Estado do Paraná. Os antígenos de superfície O-K e de aderência foram identificados no Centro de Pesquisas Veterinárias Desidério Finamor (RS), e na UNICAMP (SP), respectivamente. Os principais sorogrupos mais prevalentes foram 0138:K81 e 0141:K85, ocorrendo na mesma proporção, em 9 (21,4\%) cepas; O139:K82 em 4 $(9,5 \%)$ e 0149:K91 em $3(7,1 \%)$ totalizando 25 $(59,4 \%)$ cepas. Os sorogrupos menos prevalentes totalizaram $4(9,5 \%)$ cepas e foram identificados como O35:K"V79", O108:K"V189", O115:K"V165" e O119:K"V113". Quanto aos antígenos de aderência, a fímbria K88 foi detectada em $22(52,4 \%)$ cepas. O antígeno F165 ocorreu em $5(11,9 \%)$ cepas sendo este o primeiro relato da ocorrência deste antígeno em cepas ETEC infectando suínos no Brasil. Baseado no levantamento sorológico concluiu-se que a inclusão nas vacinas dos sorogrupos O-K mais prevalentes e dos antígenos de aderência clássicos bem como do F165 poderá conferir proteção mais efetiva na prevenção da colibacilose dos leitões no Estado do Paraná.
\end{abstract}

Palavras-chave: colibacilose; leitões; diarréia; sorotipagem; prevalência.

\begin{abstract}
The aim of the present work was the serological characterization of 42 strains of Escherichia coli isolated at the Center of Veterinary Diagnostic Marcos Enrietti, in Curitiba, PR from out breaks of swine diarrhea in the State of Paraná. The surface $\mathrm{O}-\mathrm{K}$ and adherence antigens were identified at the Center of Veterinary Researches Desidério Finamor (RS) and at UNICAMP (SP), respectively. The main serogroups involved were 0138:K81 and 0141:K85 which occurred in the same proportion in $9(21.4 \%)$ strains; $4(9.5 \%)$ strains were O139:K82 and $3(7.1 \%)$ were $0149: \mathrm{K} 91$. The serogroups O35:K"V79", O108:K"V189", O115:K"V165" and O119:K"V113" were found in only one sample each $(2.4 \%)$ of the strains. In relation to fimbrial antigens, K88 was detected in $22(52.4 \%)$ strains and the F165 in $5(11.9 \%)$ strains. This is the first report of the occurrence of the fimbrial antigen named F165 in Brazil. It was concluded that the inclusion of these more prevalent serogroups $\mathrm{O}-\mathrm{K}$ as well as the classical fimbriae and the F165 antigen could give more protection against the colibacillosis of piglets in Parana State.
\end{abstract}

Key-words: colibacillosis; piglets; diarrhea; serotyping; prevalence. 


\section{INTRODUÇÃO}

Dentre as doenças infecciosas afetando os suínos, a colibacilose destaca-se como uma das principais responsáveis pelas altas taxas de morbidade e mortalidade em leitões do nascimento ao desmame (TZIPORI et al., 1980; BRITO et al., 1995). Cepas patogênicas de Escherichia coli (E. coli) são responsáveis por quadros clínicos denominados de diarréia neonatal e da terceira semana, diarréia do desmame e doença do edema (SOJKA, 1971; FAIRBROTHER, 1992). Em um levantamento sobre a produção suína nos Estados Unidos, foi estimado que $7 \%$ de leitões entre 0 e 4 dias de idade apresentaram diarréia, a maioria sendo causada pela $E$. coli onde cerca de $50 \%$ daqueles animais morreram (USDA, 1991). BARCELLOS et al., (1980), obtiveram entre 433 amostras de fezes diarréicas, 338 $(78 \%)$ isolamentos do agente demonstrando assim a importância do patógeno no contexto geral das causas das doenças entéricas nesta espécie animal (BARCELLOS et al., 1980).

A participação de alguns sorotipos em casos de diarréia e doença do edema em suínos está bem estabelecida e ao detectar o sorotipo responsável pode-se estabelecer com mais precisão um esquema de vacinação preventivo mais adequado (SOJKA, 1971; BARCELLOS et al., 1980). Para tanto, a classificação sorológica das cepas de $E$. coli está baseada na identificação de seus quatro antígenos de superfície: $\mathrm{O}$ (antígeno somático); $\mathrm{K}$ (antígeno capsular), $\mathrm{H}$ (antígeno flagelar) e $\mathrm{F}$ (antígeno fimbrial) (ORSKOV et al., 1977; ORSKOV e ORSKOV, 1983). Pesquisas relacionadas aos antígenos de superfície O-K em E. coli foram realizadas no Brasil (BARCELLOS e BAPTISTA, 1977; OLIVEIRA et al., 1981; CASTRO et al., 1984; GATTI et al., 1985; BRITO et al., 1995; FERREIRA et al., 1997) e em diversos países (GONZALES e BLANCO, 1986; HAREL et al., 1991; NAGY et al., 1992; SALAJKA et al., 1992; IMBERECHTS et al., 1994; NGELEKA, 2002) evidenciando a participação de sorotipos O-K mais prevalentes em casos de colibacilose suína. Outras pesquisas identificaram os principais antígenos de aderência associados às cepas patogênicas causadoras de diarréia (OLIVEIRA et al., 1981; CASTRO et al., 1984; GATTI et al., 1985; YANO et al., 1986; GARCÍA et al., 1987; CARVALHO et al., 1991; HAREL et al., 1991; NAGY et al., 1992; SALAJKA et al., 1992; FERREIRA et al., 1997; NGELEKA, 2002).

Visando contribuir para um melhor esclarecimento sobre as cepas de $E$. coli envolvidas em diarréias em leitões no Estado do Paraná, o presente trabalho tem como objetivos principais determinar a freqüência de antígenos somáticos, capsulares e fimbriais em cepas isoladas de leitões nos períodos neonatal e de pós-desmame visando a inclusão dos mesmos em vacinas comerciais atualmente em uso nesta região do Brasil.

\section{MATERIAL E MÉTODOS}

Quarenta e duas cepas de E.coli isoladas no Centro de Diagnóstico Marcos Enrietti de amostras fecais de leitões com diarréia provenientes de distintas granjas suinícolas localizadas no Estado do Paraná, foram encaminhados para sorotipagem em centros de referência. A verificação dos antígenos O-K, segundo SOJKA (1971), e dos antígenos de aderência (K88, K99, 987P, F41 e F165) foi realizada no Centro de Pesquisas Veterinárias Desidério Finamor (RS) e no Laboratório de Microbiologia da UNICAMP (SP), respectivamente.

\section{RESULTADOS}

Na TABELA 1 são apresentados os resultados das sorotipagens das 42 cepas de E.coli. Verificou-se a predominância de dois sorogrupos, 0138:K81 e O141:K85 em igual proporção com $9(21,4 \%)$ cepas identificadas. $O$ terceiro e quarto sorogrupos mais predominantes foram 0139:K82 com 4 cepas (9,5\%) e 0149:K91 com 3 cepas $(7,1 \%)$, respectivamente. O somatório do número de cepas bem como das percentagens destes quatro sorogrupos mais prevalentes totalizou 25 cepas $(59,0 \%)$. As demais 4 cepas foram identificadas como pertencendo a 4 sorogrupos distintos O35:K"V79", 1 cepa $(2,4 \%)$, O108:K"V189", 1 cepa (2,4\%), O115:K"V165", 1 сера $(2,4 \%)$ e O119:K"V113", 1 cepa (2,4\%). Não foi possível a identificação precisa dos antígenos O-K de 13 cepas $(31,0 \%)$ devido a fatores tais como a não reação com os anti-soros utilizados, reações cruzadas a mais de um anti-soro ou devido a cepas auto-aglutinantes. Com relação aos antígenos de aderência expressados nas 29 cepas O-K acima sorotipadas, observou-se que entre as 25 cepas (pertencentes a 4 sorogrupos O-K mais prevalentes), 14 delas (56\%) expressaram os antígenos de aderência K88 e uma cepa (4\%) o antígeno F165. Entre os 4 sorogrupos menos prevalentes sorotipados, em 3 $(75,0 \%)$ deles o antígeno K88 também foi expressado. No somatório final entre 29 cepas O-K sorotipadas, 17 $(58,6 \%)$ delas expressaram o antígeno K88 e 1 (3,4\%) o antígeno F165. Em $13(31,0 \%)$ cepas O-K não identificadas, $5(38,4 \%)$ delas também expressaram o antígeno K88, 4 (30,6\%) o antígeno F165 e em 4 (30,6\%) delas não foi possível identificar os antígenos de aderência por se apresentarem rugosas. Com relação apenas aos antígenos de aderência, entre as 42 cepas analisadas, $22(52,4 \%)$ expressaram antígenos K88 e $5(11,9 \%)$ expressaram o antígeno F165, enquanto que em 15 
Caracterização sorológica dos Antígenos de superfície em cepas de escherichia

Coli isoladas de suínos com diarréia no Estado do Paraná

TABELA 1 - ASSOCIAÇÃO ENTRE SOROGRUPOS O-K E FÍMBRIAS

\begin{tabular}{ccccccccc}
\hline $\begin{array}{c}\text { Sorogrupos } \\
\text { O-K }\end{array}$ & $\mathrm{N}^{\circ}$ Cepas & $\%$ & $\mathrm{~K} 88$ & $\%$ & $\begin{array}{c}\text { Fímbrias } \\
\text { F165 } \%\end{array}$ & $\%$ & $\mathrm{NI}$ & $\%$ \\
\hline O138:K81 & 9 & 21,4 & 4 & 44,4 & 0 & $0,0 \%$ & 5 & 55,6 \\
\hline O141:K82 & 9 & 21,4 & 8 & 88,8 & 1 & 11,2 & 0 & 0,0 \\
\hline O139:K85 & 4 & 9,5 & 0 & 0,0 & 0 & 0,0 & 4 & 100,0 \\
\hline O149:K91 & 3 & 7,1 & 2 & 76,6 & 0 & 0,0 & 1 & 23,4 \\
\hline O35 & 1 & 2,4 & 0 & 0,0 & 0 & 0,0 & 1 & 100,0 \\
\hline O108 & 1 & 2,4 & 1 & 100,0 & 0 & 0,0 & 0 & 0,0 \\
\hline O115 & 1 & 2,4 & 1 & 100,0 & 0 & 0,0 & 0 & 0,0 \\
\hline O119 & 1 & 2,4 & 1 & 100,0 & 0 & 0,0 & 0 & 0,0 \\
\hline NI & 13 & 31,0 & 5 & 38,4 & 4 & 30,6 & 4 & 30,6 \\
\hline TOTAL & 42 & 100,0 & 22 & & 5 & & 15 & \\
\hline
\end{tabular}

$\mathrm{NI}$ - não identificados

cepas as fimbrias não foram identificadas.

\section{DISCUSSÃO}

A presente pesquisa aborda a identificação dos antígenos de superfície de cepas isoladas de surtos de colibacilose em leitões no Estado do Paraná. Quanto aos antígenos O-K verificou-se a freqüência maior dos sorogrupos 0138:K81 e do 0141:K85 com 9 cepas cada (21,4\%); 0139:K82 com 4 cepas (9.5\%). Portanto observou-se o predomínio destes sorogrupos em $50 \%$ das cepas investigadas. Relacionando os artigos científicos realizadas no Brasil a este respeito, verifica-se que BARCELLOS et al. (1980) bem como GATTI et al. (1985), em pesquisa semelhante também verificaram a presença dos sorogrupos 0141 e 0138 como os mais prevalentes no Estado do Rio Grande do Sul. Os índices encontrados pelos pesquisadores quanto a esses sorogrupos foram de $25,7 \%$ e $28,7 \%$ e $23,5 \%$ e $19,8 \%$, respectivamente. No Estado de Santa Catarina, CASTRO et al. (1984) também identificaram o antígeno 0138 em 5,8\% das cepas com o predomínio do sorogrupo 0149 em $32,3 \%$. Este último sorogrupo foi identificado na presente pesquisa em $7,1 \%$ das cepas enquanto que BARCELLOS et al. (1980) e GATTI et al. (1985) o identificaram em 7,4\% e $11,7 \%$, respectivamente. Devido a proximidade geográfica destes três estados considerados os maiores produtores de suínos do país e as relações comerciais entre eles que envolvem a aquisição de animais reprodutores, é de acreditar-se que as cepas encontradas neste estudo estejam amplamente disseminadas e estabelecidas na região Sul do país.
Mesmo assim, peculiaridades regionais fazem com que uma cepa seja mais predominante do que outra como foi verificado no presente trabalho, o que demonstra a necessidade de vigilâncias periódicas quanto às avaliações dos sorogrupos mais prevalentes. Esta correlação regional também foi verificada por GONZALES e BLANCO (1986) e GARABAL et al. (1996) em pesquisas realizadas na Espanha, os quais identificaram o sorotipo 0141 como o mais freqüentemente presente, correspondendo a $36,5 \%$ e $13,2 \%$, respectivamente, mostrando a similaridade de resultados e o valor epidemiológico regional na realização destes levantamentos antigênicos em cepas patogênicas.

A composição das vacinas preventivas comerciais contra a colibacilose necessitará sempre destas investigações antigênicas preliminares, sob o risco de mostrarem-se ineficazes quando do seu uso em propriedades com surtos freqüentes. Fica também evidente que vacinas importadas contra a colibacilose dos leitões teriam pouca eficácia na prevenção de surtos, pois os sorotipos presentes numa região ou país não são necessariamente os mesmos. Por outro lado, face aos resultados semelhantes encontrados nestas regiões suinícolas do nosso país, as vacinas que contivessem os 4 antígenos $\mathrm{O}-\mathrm{K}$ predominantes (O138:K81, O141:K85, O139:K82 e 0149:K91) poderiam ser utilizadas em animais dos três estados, pois $59 \%$ das cepas patogênicas sorotipadas pertenceram a estes sorogrupos. A presença do antígeno de aderência $\mathrm{K} 88 \mathrm{em} 60,0 \%$ das cepas (independentemente do antígeno O-K apresentado) e do antígeno F165 em 14,3\% demonstra que a inclusão desta última fimbria de aderência na composição vacinal será de vital importância 
para uma efetiva proteção. Atualmente, as vacinas contra a colibacilose suína não apresentam em sua composição a fimbria F165. A expressão do antígeno F165 em cepas de $E$. colié pela primeira vez relatada em nosso país, comprovando a necessidade deste monitoramento antigênico, pois a variabilidade das cepas e de seus antígenos de aderência é esperada, por tratar-se de um processo dinâmico em que podem estar envolvidos plasmídeos de transferência disseminando estes fatores de virulência entre cepas de E. coli. Devido a pressão vacinal exercida pelo uso constante de imunógenos contendo os antígenos de aderência clássicos, como o K88 e K99 é de se esperar o surgimento de cepas expressando novas fimbrias ainda não detectadas (SALAJKA et al., 1992; NGELEKA, 2002). Métodos alternativos mais sensíveis têm sido empregados na identificação de cepas ETEC com o objetivo de detectar genes responsáveis pela expressão de fímbrias em E. coli não necessitando a utilização de anti-soros específicos nem a utilização de meios de cultura promotores da produção destes antígenos de aderência (DEBROY e MADDOX, 2001).

\section{REFERÊNCIAS}

BARCELLOS, D.E.S.N.; GUIZZARD, I.I.; FALLAVENA, L.C.B. Freqüência e causa de diarréias em suínos nas zonas do Vale do Taquari e Missões; Rio Grande do Sul; Brasil. Boletim do Instituto de Pesquisas Veterinárias Desidério Finamor, v.7, p.27-37, 1980.

BARCELLOS, D.E.S.N.; BAPTISTA, P.J.H.P. Colibacilose suína: novos tipos sorológicos de Escherichia coli identificados em municípios do Rio Grande do Sul e Santa Catarina. Boletim do Instituto de Pesquisas Veterinárias Desidério Finamor, v.4, p.65-71, 1977.

BRITO, B.G.; FILIPPSEN, L.F.; MORES, N.; BRENTANO, L.; BRITO, M.A.V.P. Etiologia da diarréia de leitões lactentes em granjas suinícolas do sudoeste do Paraná. Semina, v.16, n.1, p.13-17, 1995.

CASTRO, A.F.P.; SERAFIM, M.B.; BRITO, J.R.F.; BARCELLOS, D.S.E.N.; COLLI, I.A.G. Virulence factors present in cultures of Escherichia coli isolated from pigs in the region of Concórdia, Santa Catarina, Brazil. Pesquisa Veterinária Brasileira, v.4, n.3, p.109-114, 1984.
DEBROY, C.; MADDOX, C.W. Identification of virulence attributes of gastrointestinal Escherichia coli isolates of veterinary significance. Animal Health Research Reviews, v.1, n.2, p.129-140, 2001.

FAIRBROTHER, J.M. Enteric colibacillosis. In: LEMAN, A.D.; STRAW, B.E.; MENGELING, W.L.; D'ALLAIRE, S.; TAYLOR, D.J. Diseases of Swine. lowa: State University Press, 1992, p. 489-497.

FERREIRA, A.J.P.; BRITO, B.G.; TAGLIARI, K.C.; SARIDAKIS, H.O. Fímbrias (F41, F42, 987P, K88, K99, Fy) e enterotoxinas (STa e LTI) em amostras de Escherichia coli isoladas de leitões com diarréia na região de Londrina - PR. In: CONGRESSO BRASILEIRO DE VETERINÁRIOS ESPECIALISTAS EM SUÍNOS. 1997, Foz do Iguaçu, Anais... Foz do Iguaçu: 1997, p.213-214.

GARABAL, J.I.; GONZALEZ, E.A.; VAZQUEZ, F.; BLANCO, J.; BLANCO, M.; BLANCO, J.E. Serogroups of Escherichia coli isolated from piglets in Spain. Veterinary Microbiology, v.48, p.113-123, 1996.

GARCÍA, D.; CAVAZZA, M.E.; BOTERO, L.; GORZIGLIA, M.; URBINA, G.; LIPRANDI, F.; ESPARZA, J. Preliminary characterization of Escherichia coli from pigs with diarrhoea in Venezuela. Veterinary Microbiology, v.13, p.47-56, 1987.

GATTI, M.S.V.; SERAFIM, M.B.; CASTRO, A.F.P. Fatores de virulência em amostras de Escherichia coli enteropatogênicas para suínos isoladas no Brasil. Revista de Microbiologia, v.16, n.1, p. 21-30, 1985.

GONZALES, E.A.; BLANCO, J. Colonization antigens, antibiotic resistance and plasmid content of enterotoxigenic Escherichia coli isolated from piglets with diarrhea in Galicia (North-Western Spain). Veterinary Microbiology, v.11, p.271-283, 1986.

HAREL, J.; LAPOINTE, H.; FALLARA, A.; LORTIE, L.A.; BIGRAS-POULIN, M.; LARIVIËRE, S.; FAIRBROTHER, J.M. Detection of genes for fimbrial antigens and enterotoxins associated with Escherichia coli serogroups isolated from pigs with diarrhea. Journal of Clinical Microbiology, v.29, n.4, p.745-752, 1991. 
Caracterização sorológica dos Antígenos de superfície em cepas de escherichia

Coli isoladas de suínos com diarréia no Estado do Paraná

IMBERECHTS, H.; BERTSCHINGER, H.U.; STAMM, M.; SYDLER, T.; POHL, P.; De GREVE, H.; HERNALSTEENS, J.P.; MONTAGU, M. VAN; LINTERMANS, P. Prevalence of F107 fimbriae on Escherichia coli isolated from pigs with oedema disease or postweaning diarrhoea. Veterinary Microbiology, v.40, p.219-230, 1994.

NAGY, B.; ARP, L.H.; MOON, H.W.; CASEY, T.A. Colonization of the small intestine of weaned pigs by enterotoxigenic Escherichia coli that lack known colonization factors. Veterinary Pathology, v.29, p.239-246, 1992.

NGELEKA, M. Isolation of a new Escherichia coli pathotype associated with diarrhea in piglets. Canadian Veterinary Journal, v.43, p.623-624, 2002.

OLIVEIRA, M.S.; CASTRO, A.F.P.; SERAFIM, M.B.; GIORGI, W. Mannose-resistant haemagglutination and colonization factors among Escherichia coli strains isolated from pigs. Veterinary Record, v.109, p.275-278, 1981.

ØRSKOV, I.; JANN, B.; JANN, K. Serology chemistry and genetics of $\mathrm{O}$ and $\mathrm{K}$ antigens of Escherichia coli. Bacteriological Reviews, v.41, p.667-710, 1977.

ØRSKOV, I.; ØRSKOV, F. Serology of Escherichia coli fimbrae. Progress in Allergy, v.33, p.80-105, 1983.

SALAJKA, E.; SALAJKOVA, Z;;ALEXA, P.; HORNICH, M. Colonization factor different from K88, K99, F41 and 987P in enterotoxigenic Escherichia coli strains isolated from postweaning diarrhea in pigs. Veterinary Microbiology, v.32, p.163-175, 1992.

SOJKA, W.J. Enteric diseases in new-born piglets, calves and lambs due to Escherichia coli infection. Veterinary Bulletin, v.41, p.509-522, 1971.

TZIPORI, S.; CHANDLER, D.; SMITH, M.; MAKING, T.; HENNSESER, D. Factors contributing to postweaning diarrhea in a large intensive piggery. Australian Veterinary Journal, v. 56, n. 6, p. 274-278, 1980.

UNITED STATES OF AMERICA DEPARTMENT OF AGRICULTURE. Preweaning morbidity and mortality: National Animal Health Monitoring System. Washington, USDA, APHIS, 1991.

YANO, T.; LEITE, D.S.; CAMARGO, I.J.B.; CASTRO, A.F.P. A probable new adhesive factor (F42) produced by enterotoxigenic Escherichia coli isolated from pigs. Microbiology and Immunology, v.30, n.6, p.495-508, 1986.

Recebido para publicação:

$30 / 05 / 2007$

Aprovado:

$26 / 11 / 2007$ 